\title{
A tris(3-pyridyl)stannane as a building block for heterobimetallic coordination polymers and supramolecular cages
}

\author{
Eric S. Yang, ${ }^{[a]}$ Alex J. Plajer, ${ }^{[a]}$ Álvaro García-Romero, ${ }^{[b]}$ Andrew D. Bond, ${ }^{[a]}$ Tanya K. Ronson, ${ }^{[a]}$ \\ Celedonio M. Álvarez, ${ }^{[b]}$ Raúl García-Rodríguez, ${ }^{,[b]}$ Annie L. Colebatch ${ }^{\star[a, c]}$ and Dominic S. Wright ${ }^{\star[a]}$
}

\begin{abstract}
The systematic assembly of supramolecular arrangements is a persistent challenge in modern coordination chemistry, especially where further aspects of complexity are concerned, as in the case of large molecular mixed-metal arrangements. One targeted approach to such heterometallic complexes is to engineer metal-based donor ligands of the correct geometry to build 3-D arrangements upon coordination to other metals. This simple idea has, however, only rarely been applied to main group metal-based ligand systems. Here we show that the new, bench-stable tris(3-pyridyl)stannane ligand $\mathrm{PhSn}(3-\mathrm{Py})_{3}$ (3-Py = 3pyridyl) provides simple access to a range of heterometallic $\mathrm{Sn}(\mathrm{IV}) /$ transition metal complexes, and that the presence of weakly coordinating counteranions can be used to build discrete molecular arrangements involving anion encapsulation. This work therefore provides a building strategy in this area, which parallels that of supramolecular transition metal chemistry.
\end{abstract}

\section{Introduction}

Pyridyl substituents are one of the most commonly encountered donor groups in coordination chemistry. However, while ligand assemblies containing 2-pyridyl-based ligands are pervasive in coordination chemistry, and counterparts containing 4-pyridyl-derived groups have been widely used in supramolecular self-assembly, ${ }^{[1]}$ their 3pyridyl relatives have thus far been underutilised. Like 4pyridyl linkers, 3-pyridyl substituents can act as metalbridging ligands, but give rise to different supramolecular architectures as a direct result of the different disposition of

[a] E. S. Yang, A. J. Plajer, Dr A. D. Bond, Dr T. K. Ronson, Dr A. L. Colebatch and Prof. D. S. Wright

Department of Chemistry

University of Cambridge

Lensfield Road, Cambridge, CB2 1EW, U.K.

E-mail: dsw1000@cam.ac.uk

[b] Á. García-Romero, C. M. Álvarez, Dr R. García-Rodríguez

GIR MIOMeT-IU Cinquima-Química Inorgánica Facultad de Ciencias

Universidad de Valladolid

Campus Miguel, Delibes, 47011 Valladolid, Spain

[c] Dr Annie L. Colebatch

Research School of Chemistry

Australian National University

Canberra, ACT, 2601, Australia

Email: annie.colebatch@anu.edu.au

Supporting information for this article is given via a link at the end of the document.

the $\mathrm{N}$-donor atoms within the ligand nodes. The comparative absence of ligands based on 3-pyridyl donor sets has been ascribed to inherent synthetic difficulties ${ }^{[1]}$ and also to their conformational flexibility, which entropically favours formation of small aggregates. ${ }^{[2]}$ Severin and coworkers have overcome this tendency by incorporating additional steric groups into bis(3-pyridyl) $\mathrm{Fe}$ clathrochelate ligands to produce $\mathrm{Pd}_{6} \mathrm{~L}_{12}{ }^{12+}$ cages, ${ }^{[2]}$ and have found that tuning the sterics alters the size of the cage. ${ }^{[3]}$ This metalloligand strategy for the construction of heterometallic supramolecular architectures has been successfully enacted for a variety of mixed transition metal systems, e.g. Fe/Pd, ${ }^{[2,4-6]} \mathrm{Fe} / \mathrm{Ru}^{[7]}$ $\mathrm{Fe} / \mathrm{Co},{ }^{[8,9]} \mathrm{Co} / \mathrm{Mn}^{[5]}$ and Ru/Pd. ${ }^{[10,11]}$ However, the use of main group metalloligands to create mixed main group/transition metal heterometallic systems is rare.

We have developed a family of tris(2-pyridyl) ligands featuring main group bridgeheads $\mathrm{E}(2-\mathrm{Py})_{3}$ (Figure $\left.1(\mathrm{a})\right)^{[12-15}$ and demonstrated that the nature of the bridgehead atom can be used to modulate structure and reactivity. ${ }^{[16]}$ However, the corresponding tris(3-pyridyl) ligands, especially those featuring main group bridgehead atoms (limited to $\mathrm{Si}, \mathrm{P}$ and $\mathrm{Bi})$, have seen only limited use in the literature. Notably, Reek has employed $\mathrm{P}(3-\mathrm{Py})_{3}$ as a ligand template to construct well-defined catalytic cavities for regioselective hydroformylation. ${ }^{[17,18]}$ Boomishankar has also used the silyl ligand $\mathrm{MeSi}(3-\mathrm{Py})_{3}$ and its 3-quinolyl analogue MeSi(3-Qy) to obtain a series of 2-D metal-organic frameworks (MOFs) ${ }^{[19]}$ and one example of a discrete molecular cage (e.g., Figure 1(b)). ${ }^{[20]}$ It can be noted, however, that although obtained in high yields these previously investigated P- and MeSi-bridgehead tris(3-pyridyl) ligands are either air sensitive and/or require chromatographic purification, making them time-consuming or difficult to prepare and handle. ${ }^{[19,21]}$

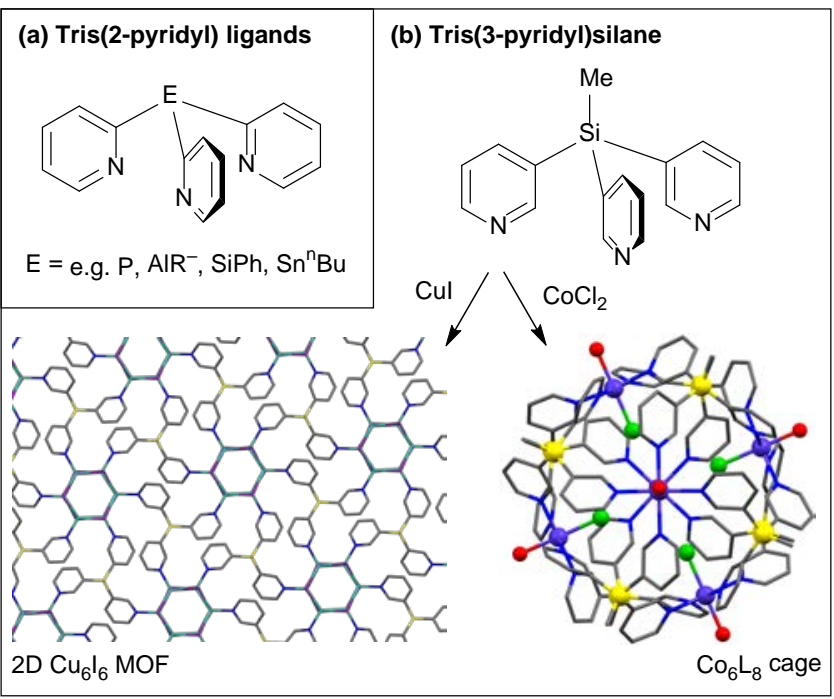


Figure 1 (a) Structure of tris(2-pyridyl) ligands containing a selection of bridgehead atoms. (b) Previous studies by Boomishankar and co-workers involving the $\mathrm{MeSi}(3-\mathrm{Py})_{3}$ ligand in which polymeric structures or discrete molecular cages were obtained, depending on the conditions and/or the transition metal coordinated. ${ }^{[19,20]}$

As part of our continued development of main group tris(pyridyl) coordination chemistry, in this paper we utilise the readily-prepared, bench-stable tris(3-pyridyl)stannane ligand $\mathrm{PhSn}(3-\mathrm{Py})_{3}$, which provides straightforward access to a range of new heterobimetallic supramolecular arrangements. We show that the architectures of complexes formed with transition metals can be strongly influenced by the nature of the bridgehead group and the presence of weakly-coordinating anions (which can promote the formation of discrete cages that involve anion encapsulation)

\section{Results and Discussion}

The ligand $\mathrm{PhSn}(3-\mathrm{Py})_{3}$ (1) was obtained in the one-pot reaction of $3-\mathrm{BrPy}$ with the turbo-Grignard ${ }^{\mathrm{i}} \mathrm{PrMgCl} \cdot \mathrm{LiCl}$ at $-15{ }^{\circ} \mathrm{C},{ }^{[22]}$ followed by addition of $\mathrm{PhSnCl}_{3}$ (Figure 2(a), see $\mathrm{ESI})$. Compound $\mathbf{1}$ is seemingly indefinitely air- and moisture-stable and is readily isolated as colourless crystals in $36 \%$ yield after crystallisation from DCM/hexane, without the need for column chromatography. In addition to analytical and spectroscopic data (see Experimental Section), the single crystal X-ray structure (Figure 2(b)) does not show $\mathrm{Mg}^{2+}$ coordination to $\mathbf{1}$ in its synthesis, as can commonly occur in this area. ${ }^{7,16}$ This is important because the presence of a contaminant metal ion can be a complication in ligand transfer to other metals. (a)

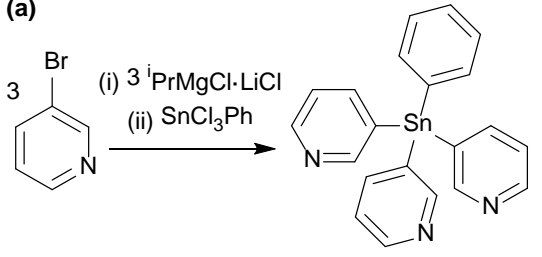

(b)

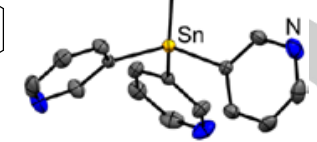

Figure 2 (a) Synthesis of $\mathrm{PhSn}(3-\mathrm{Py})_{3}$ (1). (b) X-ray crystal structure of 1. Thermal ellipsoids are drawn at $50 \%$ probability, hydrogen atoms omitted Selected bond lengths $(\AA)$ and angles $\left({ }^{\circ}\right)$ : Sn1-C1 2.139(4); C1-Sn1-C1 109.17(11), Sn1-C1-C2 120.9(3).

Slow diffusion of an MeCN solution of $\mathbf{1}$ (1 equivalent) into an MeCN solution of Cul ( 1 equivalent) over 3 days in air gave yellow crystals of $\left[\mathrm{Cu}_{2} \mathrm{I}_{2}(\mathbf{1})_{2}\right]_{\mathrm{n}}$ in $66 \%$ yield (Figure 3 ) (see Experimental Section). The X-ray crystal structure is that of a 1-D coordination polymer in which bridging ligands 1 link $\mathrm{Cu}_{2} \mathrm{I}_{2}$ units in a polymeric arrangement, using two of the three 3-Py $\mathrm{N}$ donor atoms (with the third being uncoordinated). This arrangement is very similar to that of $\left[\mathrm{Cu}_{2} \mathrm{I}_{2}\left\{\mathrm{MeSi}(3-\mathrm{Qy})_{3}\right\}_{2}\right]_{\mathrm{n}}$ obtained using the tris(3-quinolyl) ligand. ${ }^{[19]}$ However, it is interesting to note that the more closely related $\mathrm{MeSi}(3-\mathrm{Py})_{3}$ ligand does not form this structure with Cul, instead producing a 2-D $\left[\mathrm{Cu}_{6} \mathrm{I}_{6}\right]$-cluster MOF. ${ }^{11}$ Attempts to produce a similar arrangement to the latter using the same solvothermal conditions as in the

previous study only produced intractable mixtures of products, regardless of stoichiometry. Thus it appeared from this initial study that simply changing the bridgehead group from $\mathrm{MeSi}(3-\mathrm{Py})_{3}$ to $\mathrm{PhSn}(3-\mathrm{Py})_{3}$ leads to marked differences in coordination character. ${ }^{[16]}$ This can be ascribed to two factors: (i) the change in ligand bite resulting from the incorporation of a larger atom at the bridging position and (ii) potentially also to the differing steric influence of the $\mathrm{Ph}$ group of 1 compared to the Me-group of $\mathrm{MeSi}(3-\mathrm{Py})_{3}$.

(a)
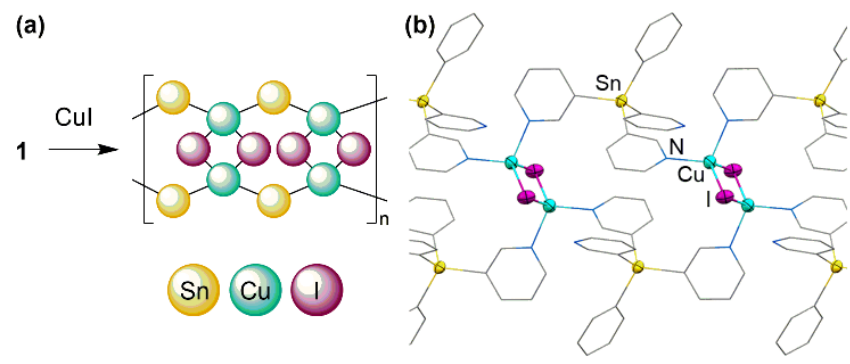

Figure 3 (a) Synthesis of $\left[\mathrm{Cu}_{2} \mathrm{I}_{2}(\mathbf{1})_{2}\right]_{\mathrm{n}}$. (b) X-ray crystal structure of $\left[\mathrm{Cu}_{2} \mathrm{I}_{2}(\mathbf{1})_{2}\right]_{\mathrm{n}}$. Displacement ellipsoids are drawn at $50 \%$ probability, $\mathrm{H}$ atoms omitted. Selected bond lengths $(\AA)$ and angles $\left({ }^{\circ}\right)$ : Cu1-N1 2.015(12), Cu1-N2 2.086(12), Cu1-I1 2.694(3)/2.577(2); N1-Cu1-N2 108.7(5), N2-Cu1-I1 $99.1(3) / 105.7(4)$

A radically different outcome is observed in the coordination of 1 to $\mathrm{CuPF}_{6}$, containing a weakly-coordinating anion. The $1: 1$ reaction of 1 with $\left[\mathrm{Cu}(\mathrm{NCMe})_{4}\right] \mathrm{PF}_{6}$ gives the complex $[\mathrm{Cu}(1)(\mathrm{NCMe})]_{4}\left[\mathrm{PF}_{6}\right]_{4}$ in $91 \%$ isolated yield (Figure 4) (see Supporting Information). The X-ray crystal structure shows a cage arrangement in which four of the ligands 1 bridge the four $\mathrm{Cu}$ centres, using all three pyridyl arms, into a discrete $\left[\{\mathrm{Cu}(\mathbf{1})(\mathrm{NCMe})\}_{4}\left(\mathrm{CPF}_{6}\right)\right]^{3+}$ cation. The $\mathrm{Cu}(\mathrm{I})$ ions are also each coordinated by a MeCN molecule, resulting in a distorted tetrahedral metal geometry. One of the $\mathrm{PF}_{6}{ }^{-}$anions is encapsulated at the centre of the $\left.\left[\mathrm{Cu}(1)(\mathrm{NCMe})(\subset \mathrm{PF})_{6}\right)\right]_{4}{ }^{3+}$ cation, while the remaining three anions are located in the crystal lattice. The nearest (3-Py) C $\cdots F$ contacts to the encapsulated $\mathrm{PF}_{6}{ }^{-}$anion (3.17(1)-3.67(1) $\AA$ ) are all at or above the sum of the van der Waals radii of $F$ and $C(3.17$ $\AA),{ }^{[23]}$ with the Py rings tilted away from the centroid of the cage in order to accommodate the $\mathrm{PF}_{6}{ }^{-}$anion in the cavity.

(a)

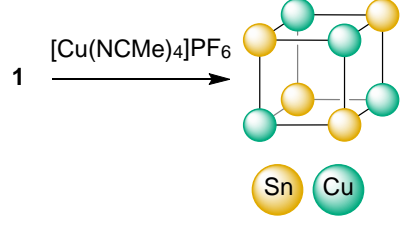

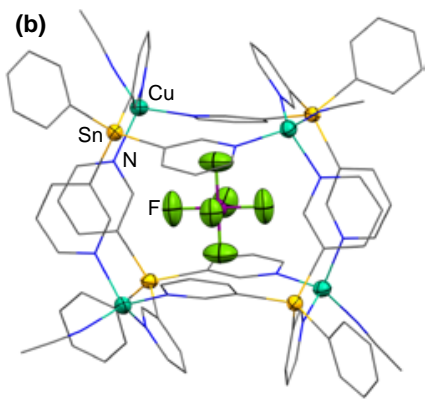

Figure 4 (a) Synthesis of the cage $\left[\mathrm{Cu}(\mathbf{1})\left(\mathrm{NCMe}_{3}\right]_{4}\left[\mathrm{PF}_{6}\right]_{4}\right.$. (b) X-ray crysta structure of $[\mathrm{Cu}(\mathbf{1})(\mathrm{NCMe})]_{4}\left[\mathrm{PF}_{6}\right]_{4}$. Displacement ellipsoids are drawn at $50 \%$ probability, hydrogen atoms and exo- $\mathrm{PF}_{6}{ }^{-}$ions omitted. Selected bond lengths $(\AA)$ and angles ( ${ }^{\circ}$ : Cu1-N1 2.026(7), Cu1-N7 1.951(9); N1-Cu1-N5 107.9(3), N1-Cu1-N7 122.9(3), C4-Sn1-C39 108.5(3). 
${ }^{1} \mathrm{H}$ and ${ }^{19} \mathrm{~F}$ NMR spectroscopic studies of $\left[\{\mathrm{Cu}(\mathbf{1})(\mathrm{NCMe})\}_{4}(\subset \mathrm{CPF})\right]^{3+}$ in $\mathrm{CD}_{3} \mathrm{CN}$ indicate dynamic behaviour. At $298 \mathrm{~K}$ the ${ }^{1} \mathrm{H}$ NMR spectrum consists of broad signals that have similar chemical shifts to those observed for the free ligand 1, together with a set of lower intensity signals (ESI, Figure S5). As the temperature is decreased the latter signals increase in intensity and are practically the only species observed at $228 \mathrm{~K}$. While the ${ }^{19} \mathrm{~F}$ NMR spectrum above $298 \mathrm{~K}$ indicates only one (averaged) $\mathrm{PF}_{6}$ environment, below $228 \mathrm{~K}$ two major $\mathrm{PF}_{6}{ }^{-}$environments are found at $\delta-72.4\left(3 \mathrm{~F},{ }^{1} J_{\mathrm{P}-\mathrm{F}}=706 \mathrm{~Hz}\right)$ and $-71.0\left(1 \mathrm{~F},{ }^{1} J_{\mathrm{P}-\mathrm{F}}=\right.$ $717 \mathrm{~Hz}$ ) ppm, together with a further (minor) $\mathrm{PF}_{6}$ environment at $\delta-70.9 \mathrm{ppm}$ (Figure 5). The ${ }^{19} \mathrm{~F}$ and ${ }^{1} \mathrm{H}$ NMR spectra are also concentration-dependent, with the lowtemperature species being favoured in more concentrated samples and the high-temperature species being favoured in dilute solutions (ESI, Figure S7). The concentration- and temperature-dependence of the ${ }^{1} \mathrm{H}$ and ${ }^{19} \mathrm{~F}$ NMR spectra are consistent with a dynamic process involving dissociation of the cage $[\mathrm{Cu}(\mathbf{1})(\mathrm{NCMe})]_{4}\left[\mathrm{PF}_{6}\right]_{4}$ into smaller species at higher temperatures and lower concentrations. Variabletemperature NMR experiments also confirm that the observed equilibrium is completely reversible. On the basis of the integration of the ${ }^{19} \mathrm{~F}$ NMR signals at $228 \mathrm{~K}$, we assign the resonance at $\delta-71.0$ to the cage-encapsulated $\mathrm{PF}_{6}{ }^{-}$ environment of the $\left[\{\mathrm{Cu}(\mathbf{1})(\mathrm{NCMe})\}_{4}\left(\subset \mathrm{PF}_{6}\right)\right]^{3+}$ cation and the resonance at $\delta-72.4 \mathrm{ppm}$ to the free $\mathrm{PF}_{6}{ }^{-}$counter-anions (found in the expected $1: 3$ ratio, respectively).

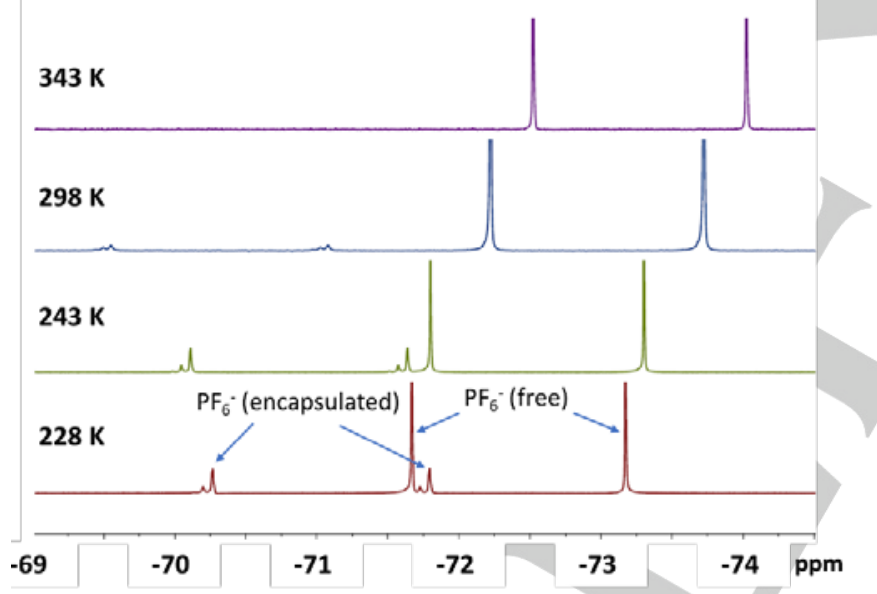

Figure $5{ }^{19} \mathrm{~F}$ NMR spectra of $[\mathrm{Cu}(\mathbf{1})(\mathrm{NCMe})]_{4}\left[\mathrm{PF}_{6}\right]_{4}$ at $343 \mathrm{~K}$ (top), $298 \mathrm{~K}$ (upper-middle), $243 \mathrm{~K}$ (lower-middle) and $228 \mathrm{~K}$ (bottom).

Further support for the previous conclusion comes from ${ }^{1} \mathrm{H}$ and ${ }^{19} \mathrm{~F}$ DOSY NMR experiments (Figure 6). ${ }^{19} \mathrm{~F}$ DOSY NMR experiments at $228 \mathrm{~K}$ show two markedly different diffusion coefficients for the doublet resonances at $\delta-72.4$ (3 F, 6.19 $\left.\times 10^{-10} \mathrm{~m}^{2} \mathrm{~s}^{-1}\right)$ and $-71.0\left(1 \mathrm{~F}, 2.06 \times 10^{-10} \mathrm{~m}^{2} \mathrm{~s}^{-1}\right)$. The diffusion coefficient extracted from ${ }^{1} \mathrm{H}$ DOSY $\left(2.16 \times 10^{-10}\right.$ $\mathrm{m}^{2} \mathrm{~s}^{-1}$ ) is identical to that for the ${ }^{19} \mathrm{~F}$ NMR resonance at $\delta$ $-71.0 \mathrm{ppm}$ at this temperature (Figure 6), supporting the conclusion that this resonance corresponds to the encapsulated $\mathrm{PF}_{6}{ }^{-}$anion of the intact $\left[\mathrm{Cu}(1)(\mathrm{NCMe})\left(\mathrm{CPF}_{6}\right)\right]_{4}{ }^{3+}$ cation, while the free $\mathrm{PF}_{6}{ }^{-}$ counterions at $\delta-72.4 \mathrm{ppm}$ diffuse much faster. The minor ${ }^{19} \mathrm{~F}$ resonance at $\delta-70.9 \mathrm{ppm}$ has a very similar diffusion coefficient to the encapsulated $\mathrm{PF}_{6}{ }^{-}$anion, suggesting that this arises from an encapsulated $\mathrm{PF}_{6}{ }^{-}$anion within a cage closely related to the $[\mathrm{Cu}(\mathbf{1})(\mathrm{NCMe})]_{4}{ }^{4+}$ cation.

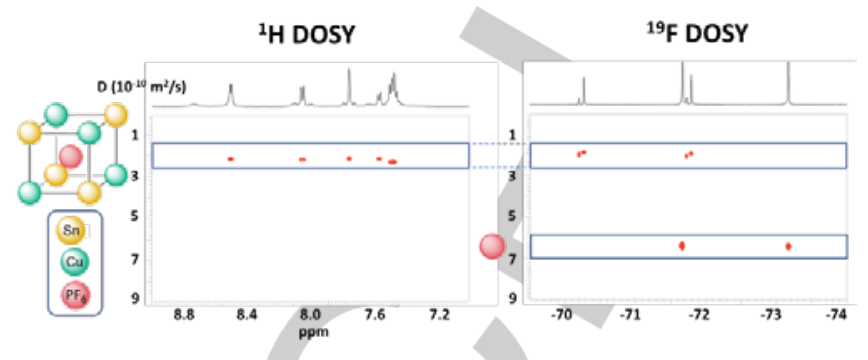

Figure $6{ }^{1} \mathrm{H}$ DOSY (left) and ${ }^{19} \mathrm{~F}$ DOSY (right) of $[\mathrm{Cu}(\mathbf{1})(\mathrm{NCMe})]_{4}\left[\mathrm{PF}_{6}\right]_{4}$ in $\mathrm{CD}_{3} \mathrm{CN}$ at $228 \mathrm{~K}$. The ${ }^{19} \mathrm{~F}$ DOSY shows that the encapsulated $\mathrm{PF}_{6}{ }^{-}$anion diffuses with the same diffusion coefficient $\left(2.06 \times 10^{-10} \mathrm{~m}^{2} \mathrm{~s}^{-1}\right)$ as that observed in the ${ }^{1} \mathrm{H}$ DOSY $\left(2.16 \times 10^{-10} \mathrm{~m}^{2} \mathrm{~s}^{-1}\right)$ for the intact cage, while the free $\mathrm{PF}_{6}{ }^{-}$counterions diffuse much faster.

In contrast, the $1: 1$ reaction of 1 with $\mathrm{AgPF}_{6}$ in $\mathrm{MeCN}$ does not result in the formation of a discrete molecular structure. While the ligands 1 adopt a similar coordination mode to that in $[\mathrm{Cu}(\mathbf{1})(\mathrm{NCMe})]_{4}\left[\mathrm{PF}_{6}\right]_{4}$, involving all three of the pyridyl-N atoms, the product $\left\{[\mathrm{Ag}(\mathbf{1})(\mathrm{NCMe})] \mathrm{PF}_{6} \cdot \mathrm{OEt}_{2}\right\}_{\mathrm{n}}$ is a 2D-coordination polymer (Figure 7) (see Experimental Section). The network is composed of fused $\mathrm{Ag}_{3} \mathrm{Sn}_{3}$ rings, with the $\mathrm{PF}_{6}{ }^{-}$anions interspersed within the 2-D MOF, and forming weak $\mathrm{F} \cdots \mathrm{Ag}$ interactions with some of the $\mathrm{Ag}^{+}$ cations (less than the sum of the van der Waals radii). The presence of these $\mathrm{F} \cdots \mathrm{Ag}$ interactions is not surprising bearing in mind the larger ionic radius and more electropositive character of $\mathrm{Ag}^{+}$, and provides a potential reason why a polymeric structure is formed in this case rather than a discrete cage (cf. no such interactions in $\left.[\mathrm{Cu}(\mathbf{1})(\mathrm{NCMe})]_{4}\left[\mathrm{PF}_{6}\right]_{4}\right)$. Variable-temperature ${ }^{1} \mathrm{H}$ and ${ }^{19} \mathrm{~F}$ NMR spectroscopic studies in MeCN show that a single species is present in solution, which does not involve $\mathrm{PF}_{6}$ encapsulation (Supporting Information, Figures S11-15).

(a)
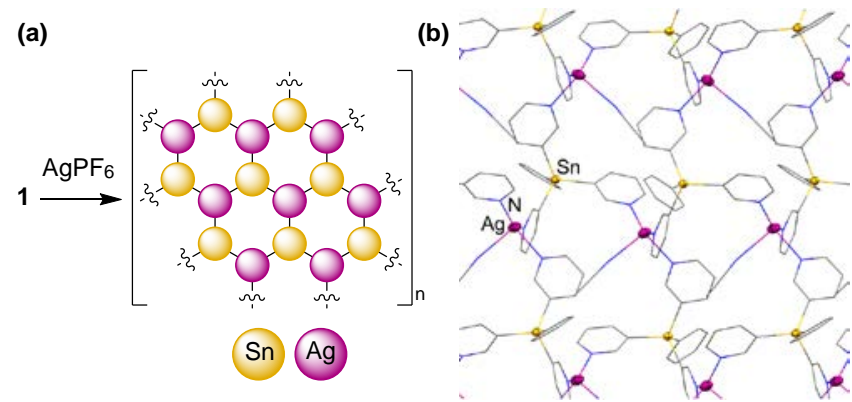

Figure 7 (a) Synthesis of $\left\{[\mathrm{Ag}(\mathbf{1})(\mathrm{NCMe})] \mathrm{PF}_{6} \cdot \mathrm{OEt}_{2}\right)_{\mathrm{n}}$. (b) X-ray crystal structure of the $2 \mathrm{D}$ sheet $\left\{[\mathrm{Ag}(\mathbf{1})(\mathrm{NCMe})] \mathrm{PF}_{6} \cdot \mathrm{OEt}_{2}\right\}_{n}$. Displacement ellipsoids are drawn at $50 \%$ probability, $\mathrm{H}$ atoms, $\mathrm{PF}_{6}{ }^{-}$anions and $\mathrm{Et}_{2} \mathrm{O}$ solvent molecules in the lattice are omitted. Selected bond lengths $(\AA)$ : Ag-N range 2.219(4)-2.628(6).

Attempts to extend this work to $\mathrm{Au}(\mathrm{I})$ by reaction of 1 with $\mathrm{AuCl}(\mathrm{THT})(\mathrm{THT}=$ tetrahydrothiophene $)$ resulted in reduction to $\mathrm{Au}(0)$. However, coordination of $\mathbf{1}$ to other transition metals was more successful. Cobalt(II) was selected as a promising candidate as Boomishankar has reported preparation of a $\left[\mathrm{CO}_{6} \mathrm{Cl}_{6}\left\{\mathrm{MeSi}(3-\mathrm{Py})_{3}\right\}_{8}\left(\mathrm{H}_{2} \mathrm{O}\right)_{6}\right] \mathrm{Cl}_{3}$ cage using 
the same salt. $\mathrm{CoCl}_{2 .}{ }^{[20]}$ The $1: 1$ reaction of 1 with $\mathrm{CoCl}_{2}$ in $\mathrm{MeOH}$ yielded a pink solution from which a blue solid was obtained by slow solvent evaporation. Recrystallisation from $\mathrm{MeOH} / \mathrm{Et}_{2} \mathrm{O}$ yielded $\left[\mathrm{CoCl}_{2}(\mathbf{1})(\mathrm{MeOH})\right]_{\mathrm{n}}$ as pink crystals (in $47 \%$ yield) suitable for (synchrotron) X-ray crystallography (Figure 8) (see Experimental Section). The $\mathrm{MeOH}$ ligands that are coordinated to the $\mathrm{Co}^{2+}$ in the complex are highly labile and are rapidly lost when the solid complex is isolated, giving the blue solid that was originally observed. The colour change from pink to blue is consistent with a change in coordination geometry from octahedral to tetrahedral. Characterisation of $\left[\mathrm{CoCl}_{2}(\mathbf{1})(\mathrm{MeOH})\right]_{\mathrm{n}}$ by ${ }^{1} \mathrm{H} \quad \mathrm{NMR}$ spectroscopy was not possible due to the paramagnetism of $\mathrm{Co}(\mathrm{II})$.

(a)

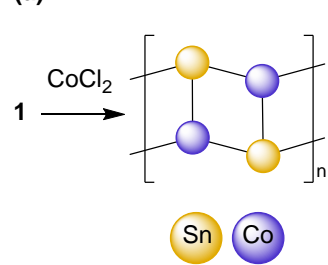

(b)

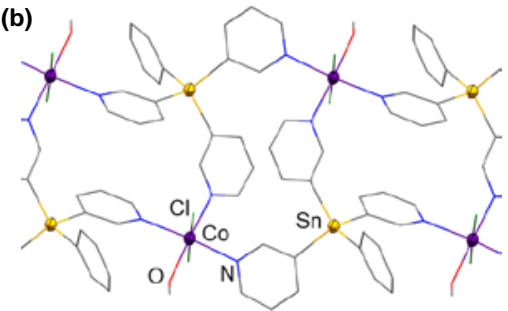

Figure 8 (a) Synthesis of $\left[\mathrm{CoCl}_{2}(\mathbf{1})(\mathrm{MeOH})\right]_{\mathrm{n}}$. (b) X-ray crystal structure of $\left[\mathrm{CoCl}_{2}(\mathbf{1})(\mathrm{MeOH})\right]_{\mathrm{n}}$. Displacement ellipsoids are drawn at $50 \%$ probability, $\mathrm{H}$ atoms omitted. Selected bond lengths $(\AA)$ and angles $\left(^{\circ}\right)$ : Co1-N1 2.151(3), Co1-O1 2.130(2), Co1-Cl1 2.4495(9), Co1-Cl2 2.4574(9); N1-Co1-N2 91.76(10), N2-Co1-N3 175.79(10)

The solid-state structure of $\left[\mathrm{CoCl}_{2}(\mathbf{1})(\mathrm{MeOH})\right]_{\mathrm{n}}$ is that of a 1D coordination polymer composed of fused $\mathrm{CO}_{2} \mathrm{Sn}_{2}$ rings, in which the three 3-Py arms of each of the ligands 1 bridge the $\mathrm{Co}$ (II) centres. The formation of this coordination polymer is distinctly different from the $\left[\mathrm{Co}_{6} \mathrm{Cl}_{6}\left\{\mathrm{MeSi}(3-\mathrm{Py})_{3}\right\}_{8}\left(\mathrm{H}_{2} \mathrm{O}\right)_{6}\right]^{3+}$ cage arrangement obtained using the analogous silicon ligand $\mathrm{MeSi}(3-\mathrm{Py})_{3}$ with $\mathrm{CoCl}_{2}$ (Figure 1(b)), ${ }^{[20]}$ again suggesting the importance of the steric and geometric profile of the bridgehead group of the tris(pyridyl) ligand in architectural control.

The influence of a weakly-coordinating anion on the structure of the product was investigated using $\mathrm{Co}\left(\mathrm{BF}_{4}\right)_{2} \cdot 6 \mathrm{H}_{2} \mathrm{O}$ in place of $\mathrm{CoCl}_{2}$ (Figure 9a). Slow diffusion of a layered $\mathrm{MeCN}$ solution of $\mathrm{Co}\left(\mathrm{BF}_{4}\right)_{2} \cdot 6 \mathrm{H}_{2} \mathrm{O}$ into a $\mathrm{CH}_{2} \mathrm{Cl}_{2}$ solution of 1 at $-30{ }^{\circ} \mathrm{C}$ for one week produced pink needles, identified by X-ray crystallography as $\left[\mathrm{Co}_{5}(\mathbf{1})_{6}\left(\mathrm{H}_{2} \mathrm{O}\right)_{6}(\mathrm{NCMe})_{6}\right]\left[\mathrm{BF}_{4}\right]_{10}$ (in $58 \%$ yield) (see Experimental Section) (Figure 9b). The X-ray data show a rapid drop-off in intensity as a function of scattering angle, leading to challenges with the refinement (see ESI), but the connectivity and structural arrangement of the complex are proved unambiguously. The structure was confirmed for a number of crystals obtained from different reaction batches. The structure contains a cationic $\left[\mathrm{CO}_{5}(\mathbf{1})_{6}\left(\mathrm{H}_{2} \mathrm{O}\right)_{6}(\mathrm{NCMe})_{6}\left(\mathrm{CBF}_{4}\right)_{2}\right]^{8+}\left(\mathrm{CO}_{5} \mathrm{Sn}_{6}\right)$ cage in which two $\mathrm{BF}_{4}{ }^{-}$anions are encapsulated (with the remaining eight residing in the crystal lattice). The five $\mathrm{Co}$ (II) atoms are arranged in a trigonal bipyramid, with each of the six faces of the trigonal bipyramid being face-capped by ligands 1 (which use all three of the 3-Py-N atoms). This trigonal bipyramidal $\mathrm{CO}_{5}$ core is inscribed within a surrounding $\mathrm{Sn}_{6}$ triangular prism, maintaining overall approximate $C_{3}$ symmetry (Figure 9c). While the axial Co(II) ions are coordinated by three (3$\mathrm{Py}) \mathrm{N}$ atoms, the equatorial $\mathrm{Co}(\mathrm{II})$ ions are coordinated by four (3-Py) $\mathrm{N}$ atoms. In addition, these $\mathrm{Co}$ (II) centres are each bonded to an $\mathrm{H}_{2} \mathrm{O}$ ligand which is located on the internal surface of the cage and are involved in $\mathrm{H} \cdots \mathrm{F} \mathrm{H}$ bonding to the encapsulated $\mathrm{BF}_{4}{ }^{-}$anions $(\mathrm{O} \cdots \mathrm{F}$ range 2.74 $2.98 \AA$; cf. sum of van der Waals radii of $B$ and $F 2.99 \AA$ ).

\section{(a)}

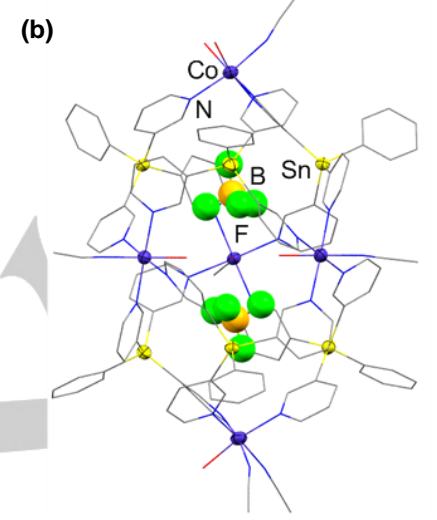

(c)
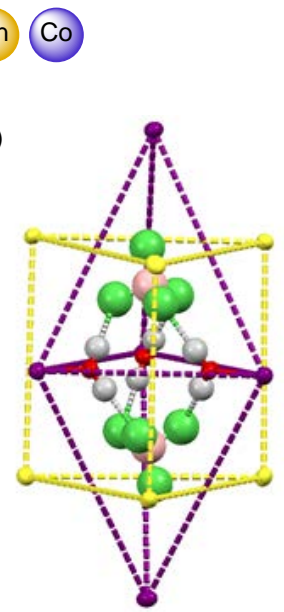

Figure 9 (a) Synthesis of $\left[\mathrm{CO}_{5}(\mathbf{1})_{6}\left(\mathrm{H}_{2} \mathrm{O}\right)_{6}(\mathrm{NCMe})_{6}\right]\left[\mathrm{BF}_{4}\right]_{10}$. (b) X-ray crystal structure of the cation $\left.\left[\mathrm{CO}_{5}(1)_{6}\left(\mathrm{H}_{2} \mathrm{O}\right)_{6}(\mathrm{NCMe})_{6}\right)\left(\subset \mathrm{BF}_{4}\right)_{2}\right]^{8+}$. Displacement ellipsoids are drawn at $50 \%$ probability, $\mathrm{H}$ atoms and exo- $\mathrm{BF}_{4}^{-}$ions omitted. Selected bond lengths $(\AA)$ and angles $\left({ }^{\circ}\right)$ : Co- $\mathrm{N}_{\text {py }}$ range 2.105(18)-2.189(17), $\mathrm{O} \ldots \mathrm{F}$ range 2.74-2.98. (c) The connectivity of the metal atoms and the $\mathrm{H}$ bonding within the core, showing the $\mathrm{H}$-bonding of the three internal $\mathrm{H}_{2} \mathrm{O}$ molecules to the $\mathrm{BF}_{4}$ anions. The complex has approximate $C_{3}$ symmetry, with the rotation axis vertical in the diagram.

Although the paramagnetic nature of $\left[\mathrm{Co}_{5}(\mathbf{1})_{6}\left(\mathrm{H}_{2} \mathrm{O}\right)_{6}(\mathrm{NCMe})_{6}\right]\left[\mathrm{BF}_{4}\right]_{10}$ hampered in-depth ${ }^{1} \mathrm{H} \mathrm{NMR}$ spectroscopic studies, the ${ }^{11} \mathrm{~B}$ and ${ }^{19} \mathrm{~F}$ NMR spectra in MeCN at room temperature support the retention of the cage structure in solution, with both showing two $\mathrm{BF}_{4}^{-}$ environments in the expected $1: 4$ ratio, along with drastically downfield-shifted resonances for the encapsulated $\mathrm{BF}_{4}{ }^{-}$anions (e.g., $\delta_{F}-112.8(1 \mathrm{~F}),-145.6(4 \mathrm{~F})$, Supporting Information, Figures S17 and 18).

\section{Conclusions}

In conclusion, the $\mathrm{PhSn}(3-\mathrm{Py})_{3}$ ligand (1) is very easily prepared in a one-pot reaction as an air- and waterstable crystalline solid, without the need for purification by column chromatography, and provides a simple building block for the construction of heterobimetallic compounds. Structural studies show that the nature of the coordination compounds formed with $\mathbf{1}$ is dependent not just on the metal ion coordinated but is also 
influenced by the coordinating or weakly-coordinating nature of the anions. While weakly-coordinating anions are known to encourage the formation of discrete cages in supramolecular transition metal chemistry and crystal engineering in general, ${ }^{[24,25]}$ this effect (as well as anion encapsulation) has not been seen previously in the tris(pyridyl) family of ligands and is a rare example in the area of main group chemistry. Comparison of our results with those involving the closely related $\mathrm{MeSi}(3-\mathrm{Py})_{3}$ ligand indicates that the steric and geometric properties of the bridgehead itself can have a major structuredirecting influence. This conclusion should provide large scope for exploring the structural influence of a range of main group bridgeheads in the future, as well as incorporation of reactive or functionalisable main group sites as a new avenue by which to access targeted reactivity in supramolecular constructs.

\section{Experimental Section}

Details of General Experimental Techniques and Instrumentation: Syntheses were carried out on a Schlenk line under a nitrogen atmosphere, unless otherwise specified. 3-Bromopyridine was distilled and dried over molecular sieves $(4 \AA)$. Other starting materials were obtained commercially from Sigma-Aldrich and Alfa-Aesar and used as received. MeCN and $\mathrm{CH}_{2} \mathrm{Cl}_{2}$ were dried over $\mathrm{CaH}_{2}$ and distilled under nitrogen. $\mathrm{Et}_{2} \mathrm{O}$ was dried over $\mathrm{Na} /$ benzophenone and distilled under nitrogen. $\mathrm{CD}_{3} \mathrm{CN}$ was degassed and dried over molecular sieves (4 $\AA$ ). Starting materials and products were handled with the aid of a nitrogenfilled glove box (Saffron type $\alpha$ ).

Room-temperature ${ }^{1} \mathrm{H},{ }^{11} \mathrm{~B}$, and ${ }^{19} \mathrm{~F}$ NMR spectra were recorded on a Bruker $400 \mathrm{MHz}$ Avance III HD Smart Probe spectrometer. Variable temperature ${ }^{1} \mathrm{H}$ and ${ }^{19} \mathrm{~F}$ NMR spectra were recorded on a Bruker 500 $\mathrm{MHz}$ Avance III HD Smart Probe spectrometer or on a $500 \mathrm{MHz}$ Agilent DD2 spectrometer. 2D ${ }^{1} \mathrm{H}$ and ${ }^{19} \mathrm{~F}$ DOSY spectra were acquired on the Agilent spectrometer using the Dbppste (DOSY) bipolar pulse pair stimulated echo pulse sequence. Typically, 32 gradient levels ranging from 6 to $55 \mathrm{G} / \mathrm{cm}$ and 16 transients were used. The diffusion time was $50 \mathrm{~ms}$ with a total diffusion-encoding gradient duration of $3 \mathrm{~ms}$. Spectra were recorded in dry $\mathrm{CDCl}_{3}$ or dry $\mathrm{CD}_{3} \mathrm{CN}$ and referenced internally to residual solvent $\left({ }^{1} \mathrm{H}\right)$ or externally to $\mathrm{CFCl}_{3}\left({ }^{19} \mathrm{~F}\right)$ or $\mathrm{BF}_{3} \cdot \mathrm{OEt}_{2}\left({ }^{11} \mathrm{~B}\right)$. NMR resonances were unambiguously assigned based on additional $2 \mathrm{D}$ NMR experiments $\left({ }^{1} \mathrm{H}-{ }^{1} \mathrm{H}\right.$ COSY). Figure 10 shows the labelling scheme for NMR assignments used in the following experimental protocols. Mass spectra were obtained by positive ion electrospray ionisation using a Thermo Fisher Orbitrap mass spectrometer. Elemental analysis for carbon, hydrogen, and nitrogen was performed using a Perkin Elmer 240 Elemental Analyser.

X-ray crystallographic data were collected using a D8-QUEST PHOTON100 diffractometer equipped with an Incoatec l $\mu \mathrm{S}$ Cu microsource (Cu Ka $\lambda=1.5418 \AA$ ). The temperature was held at $180(2) \mathrm{K}$ using an Oxford Cryosystems $\mathrm{N}_{2}$ cryostat. Data integration and reduction were undertaken with SAINT in the APEX3 software suite. Multi-scan corrections were applied using SADABS. Structures were solved using SHELXT ${ }^{[18]}$ and refined using SHELXL. ${ }^{[19]}$ Data for $\left[\mathrm{CoCl}_{2}(\mathbf{1})(\mathrm{MeOH})\right]$ were collected at Beamline 119 of Diamond Light Source employing silicon double crystal monochromated synchrotron radiation (0.6889 $\AA$ ) with $\omega$ and $\phi$ scans at $100(2) K^{[20]}$ Data integration and reduction were undertaken with Xia2. ${ }^{[21]}$ Multi-scan empirical absorption corrections were applied to the data using the AIMLESS ${ }^{[22]}$ tool in the CCP4 suite. ${ }^{[23]}$ The structure was solved using SHELXT then refined with SHELXL.

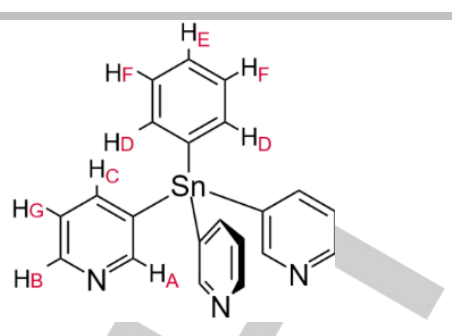

Figure 10 Labelling scheme for NMR assignments of ligand 1.

Synthesis of $\mathrm{SnPh}(3-\mathrm{Py})_{3}$ (1); 3-Pyridylmagnesium chloride lithium chloride complex was prepared in situ using a previously reported procedure. ${ }^{[2]} 3$-Bromopyridine $(0.96 \mathrm{ml}, 10.0 \mathrm{mmol})$ was added in one portion to a stirred solution of $1.3 \mathrm{M}$ isopropylmagnesium chloride lithium chloride complex in THF $(8.08 \mathrm{ml}, 10.5 \mathrm{mmol})$ at $-15^{\circ} \mathrm{C}$ under a nitrogen atmosphere. The resulting brown mixture was stirred for $15 \mathrm{~min}$ at $-10{ }^{\circ} \mathrm{C}$ Phenyltin trichloride $(0.55 \mathrm{ml}, 3.3 \mathrm{mmol})$ was added dropwise to the reaction mixture, which was then allowed to warm to room temperature and stirred overnight. The resulting white suspension was treated with water $(20 \mathrm{ml})$, and the organic phase extracted with DCM $(3 \times 15 \mathrm{ml})$. The extract was washed with brine $(15 \mathrm{ml})$, dried over anhydrous magnesium sulfate, then filtered through Celite. The solvent was removed by evaporation under reduced pressure to give a pale yelloworange solid, which was purified by recrystallisation (DCM/hexane) and washed with acetone to yield phenyltris(3-pyridyl)stannane (1) as colourless needle-like crystals $(0.52 \mathrm{~g}, 1.2 \mathrm{mmol}, 36 \%)$. Single crystals suitable for X-ray diffraction were obtained by vapour diffusion recrystallisation from $\mathrm{DCM} /$ pentane. Elemental analysis (\%) calcd for $\mathrm{C}_{21} \mathrm{H}_{18} \mathrm{~N}_{3} \mathrm{Sn}$ : C 58.65, H 3.98, N 9.77, found: C 58.50, H 3.93, N 9.68. ${ }^{1} \mathrm{H}$ NMR $\left(25^{\circ} \mathrm{C}, \mathrm{CDCl}_{3}, 400 \mathrm{MHz}\right): \delta(\mathrm{ppm})=8.74\left(\mathrm{~s}, 3 \mathrm{H}, \mathrm{H}_{\mathrm{A}}\right), 8.67\left(\mathrm{dd}, \mathrm{J}_{\mathrm{HH}}\right.$ $\left.=2 \mathrm{~Hz}, 5 \mathrm{~Hz}, 3 \mathrm{H}, \mathrm{H}_{\mathrm{B}}\right), 7.86\left(\mathrm{~d}, \mathrm{~J}_{\mathrm{HH}}=8 \mathrm{~Hz}, 3 \mathrm{H}, \mathrm{H}_{\mathrm{C}}\right), 7.56\left(\mathrm{~m}, 2 \mathrm{H}, \mathrm{H}_{\mathrm{D}}\right)$, $7.46\left(\mathrm{~m}, 3 \mathrm{H}, \mathrm{H}_{\mathrm{E} / \mathrm{F}}\right), 7.35\left(\mathrm{dd}, \mathrm{J}_{\mathrm{HH}}=5 \mathrm{~Hz}, 8 \mathrm{~Hz}, 3 \mathrm{H}, \mathrm{H}_{\mathrm{G}}\right) .{ }^{1} \mathrm{H} \mathrm{NMR}\left(25^{\circ} \mathrm{C}\right.$, $\left.\mathrm{CD}_{3} \mathrm{CN}, 400 \mathrm{MHz}\right): \delta(\mathrm{ppm})=8.70\left(\mathrm{dd}, \mathrm{J}_{\mathrm{HH}}=1 \mathrm{~Hz}, 3 \mathrm{H}, \mathrm{H}_{\mathrm{A}}\right), 8.61\left(\mathrm{dd}, \mathrm{J}_{\mathrm{HH}}\right.$ $=2 \mathrm{~Hz}, 5 \mathrm{~Hz}, 3 \mathrm{H}, \mathrm{H}_{\mathrm{B}}$ ), 7.93 (ddd, $\mathrm{J}_{\mathrm{HH}}=2 \mathrm{~Hz}, 7 \mathrm{~Hz}, \mathrm{~J}_{\mathrm{HSn}}=48 \mathrm{~Hz}, 3 \mathrm{H}, \mathrm{H}_{\mathrm{C}}$ ), $7.62\left(\mathrm{~m}, 2 \mathrm{H}, \mathrm{H}_{\mathrm{D}}\right), 7.47\left(\mathrm{~m}, 3 \mathrm{H}, \mathrm{H}_{\mathrm{E} / \mathrm{F}}\right), 7.38$ (ddd, $\mathrm{J}_{\mathrm{HH}}=1 \mathrm{~Hz}, 5 \mathrm{~Hz}, 7 \mathrm{~Hz}$, $\left.3 \mathrm{H}, \mathrm{H}_{\mathrm{G}}\right)$. HRMS-ESI $(\mathrm{m} / \mathrm{z})$ calcd for $\mathrm{C}_{21} \mathrm{H}_{18} \mathrm{~N}_{3}{ }^{120} \mathrm{Sn}_{1}\left(\mathrm{M}+\mathrm{H}^{+}\right): 432.0521$, found: 432.0518 .

Synthesis of $\left[\mathrm{Cu}_{2} \mathrm{I}_{2}(\mathbf{1})_{2}\right]_{\mathrm{n}}$ : A solution of copper(I) iodide (22 mg, 0.12 $\mathrm{mmol})$ in dry acetonitrile $(2 \mathrm{ml})$ was prepared in a narrow Schlenk flask under a nitrogen atmosphere. A solution of phenyltris(3-pyridyl)stannane (1) $(50 \mathrm{mg}, 0.12 \mathrm{mmol})$ in dry acetonitrile $(12 \mathrm{ml})$ was layered carefully on top of the copper iodide solution. The two layers were left to diffuse slowly at room temperature over $72 \mathrm{~h}$, resulting in yellow crystals that were isolated by filtration. The product $\left[\mathrm{Cu}_{2} \mathrm{I}_{2}(\mathbf{1})_{2}\right]_{n}$ was obtained as yellow crystals (49 mg, $0.079 \mathrm{mmol}, 66 \%$ ). Characterisation of the product by NMR spectroscopy and mass spectrometry was impeded by its insolubility in suitable solvents. Elemental analysis (\%) calcd for $\mathrm{C}_{42} \mathrm{H}_{34} \mathrm{Cu}_{2} \mathrm{I}_{2} \mathrm{~N}_{6} \mathrm{Sn}_{2}$ : C 40.65, H 2.76, N 6.77, found: C 40.78, H 2.68, N 6.23 .

Synthesis of $[\mathrm{Cu}(\mathbf{1})(\mathrm{NCMe})]_{4}\left[\mathrm{PF}_{6}\right]_{4} ; \mathrm{A}$ Schlenk flask was charged with tetrakis(acetonitrile)copper(I) hexafluorophosphate $(87 \mathrm{mg}, 0.23 \mathrm{mmol}$ ) in a nitrogen filled glove box. The flask was transferred to a Schlenk line and the solid dissolved in dry acetonitrile $(4 \mathrm{ml})$ to give a colourless solution. To this, a solution of phenyltris(3-pyridyl)stannane (1) (100 mg, $0.23 \mathrm{mmol})$ in dry dichloromethane $(12 \mathrm{ml})$ was added. The resulting yellow mixture was stirred at room temperature overnight, then filtered through Celite. Removal of the solvent in vacuo yielded $[\mathrm{Cu}(1)(\mathrm{NCMe})]_{4}\left[\mathrm{PF}_{6}\right]_{4}$ as a yellow solid $(0.14 \mathrm{~g}, 0.21 \mathrm{mmol}, 91 \%)$. Single crystals suitable for $\mathrm{X}$-ray diffraction were obtained by vapour diffusion recrystallisation from acetonitrile/ether. Elemental analysis (\%) calcd for $\mathrm{C}_{92} \mathrm{H}_{80} \mathrm{Cu}_{4} \mathrm{~F}_{24} \mathrm{~N}_{16} \mathrm{P}_{4} \mathrm{Sn}_{4}$ : C 40.65, H 2.97, N 8.24, found: C 41.15, H 3.29, N 8.12. ${ }^{1} \mathrm{H}$ NMR $\left(-30{ }^{\circ} \mathrm{C}, \mathrm{CD}_{3} \mathrm{CN}, 500 \mathrm{MHz}\right): \delta(\mathrm{ppm})=8.33\left(\mathrm{~d}, \mathrm{~J}_{\mathrm{HH}}=4\right.$ $\left.\mathrm{Hz}, 3 \mathrm{H}, \mathrm{H}_{\mathrm{B}}\right), 7.91\left(\mathrm{~d}, \mathrm{~J}_{\mathrm{HH}}=7 \mathrm{~Hz}, 3 \mathrm{H}, \mathrm{H}_{\mathrm{C}}\right), 7.68\left(\mathrm{~s}, 3 \mathrm{H}, \mathrm{H}_{\mathrm{A}}\right), 7.49\left(\mathrm{~d}, \mathrm{~J}_{\mathrm{HH}}=\right.$ $\left.6 \mathrm{~Hz}, 2 \mathrm{H}, \mathrm{H}_{\mathrm{D}}\right), 7.42$ (b), 7.41 (b). ${ }^{1} \mathrm{H}$ NMR $\left(70{ }^{\circ} \mathrm{C}, \mathrm{CD}_{3} \mathrm{CN}, 500 \mathrm{MHz}\right): \delta$ $(\mathrm{ppm})=8.70\left(\mathrm{~s}, 3 \mathrm{H}, \mathrm{H}_{\mathrm{A}}\right), 8.31\left(\mathrm{~d}, \mathrm{~J}_{\mathrm{HH}}=5 \mathrm{~Hz}, 3 \mathrm{H}, \mathrm{H}_{\mathrm{B}}\right), 7.97\left(\mathrm{~d}, \mathrm{~J}_{\mathrm{HH}}=7 \mathrm{~Hz}\right.$, $\left.3 \mathrm{H}, \mathrm{H}_{\mathrm{C}}\right), 7.63\left(\mathrm{~m}, 2 \mathrm{H}, \mathrm{H}_{\mathrm{D}}\right), 7.49\left(\mathrm{~m}, 3 \mathrm{H}, \mathrm{H}_{\mathrm{E} / \mathrm{F}}\right), 7.42\left(\mathrm{dd}, \mathrm{J}_{\mathrm{HH}}=5 \mathrm{~Hz}, 7 \mathrm{~Hz}\right.$, 
$\left.3 \mathrm{H}, \mathrm{H}_{\mathrm{G}}\right) .{ }^{19} \mathrm{~F}$ NMR $\left(-30{ }^{\circ} \mathrm{C}, \mathrm{CD}_{3} \mathrm{CN}, 470.6 \mathrm{MHz}\right): \delta(\mathrm{ppm})=-70.99\left(\mathrm{~d}, \mathrm{~J}_{\mathrm{FP}}\right.$ $\left.=707 \mathrm{~Hz}, \mathrm{PF}_{6}\right),-71.05\left(\mathrm{~d}, \mathrm{~J}_{\mathrm{FP}}=707 \mathrm{~Hz}, \mathrm{PF}_{6}\right),-71.12\left(\mathrm{~d}, \mathrm{~J}_{\mathrm{FP}}=707 \mathrm{~Hz}\right.$, $\left.\mathrm{PF}_{6}\right),-72.79\left(\mathrm{~d}, \mathrm{~J}_{\mathrm{FP}}=707 \mathrm{~Hz}, \mathrm{PF}_{6}\right) .{ }^{19} \mathrm{~F} \mathrm{NMR}\left(70{ }^{\circ} \mathrm{C}, \mathrm{CD}_{3} \mathrm{CN}, 470.6\right.$ $\mathrm{MHz}): \delta(\mathrm{ppm})=-73.50\left(\mathrm{~d}, \mathrm{~J}_{\mathrm{FP}}=706 \mathrm{~Hz}, \mathrm{PF}_{6}\right)$. HRMS-ESI $(\mathrm{m} / \mathrm{z})$ calcd for $\mathrm{C}_{23} \mathrm{H}_{20} \mathrm{CuN}_{4}{ }^{120} \mathrm{Sn}_{1}\left([\mathrm{Cu}(1)(\mathrm{NCMe})]^{+}\right): 535.0003$, found: 535.0010 Synthesis of $\left\{[\mathrm{Ag}(\mathbf{1})(\mathrm{NCMe})] \mathrm{PF}_{6} \cdot \mathrm{OEt}_{2}\right\}_{n} ; \mathrm{A}$ Schlenk flask was charged with silver(I) hexafluorophosphate $(59 \mathrm{mg}, 0.23 \mathrm{mmol})$ in a nitrogen filled glove box. The flask was transferred to a Schlenk line, and the solid dissolved in dry acetonitrile $(4 \mathrm{ml})$ to give a colourless solution. To this, a solution of phenyltris(3-pyridyl)stannane (1) $(100 \mathrm{mg}, 0.23 \mathrm{mmol})$ in dry dichloromethane $(12 \mathrm{ml})$ was added. The reaction mixture was stirred at room temperature overnight, then filtered through Celite. The solvent was removed in vacuo to give a colourless solid. Recrystallisation from acetonitrile/ether by liquid-diffusion yielded the product $\left\{[\mathrm{Ag}(\mathbf{1})(\mathrm{NCMe})] \mathrm{PF}_{6} \cdot \mathrm{Et}_{2} \mathrm{O}\right\}_{\mathrm{n}}$ as colourless crystals $(76 \mathrm{mg}, 0.095 \mathrm{mmol}$, 41\%). Elemental analysis (\%) calcd for $\mathrm{C}_{23} \mathrm{H}_{20} \mathrm{AgF}_{6} \mathrm{~N}_{4} \mathrm{PSn}$ : C 38.16, $\mathrm{H}$ 2.78, N 7.74, found: $\mathrm{C} 38.34, \mathrm{H} 3.06, \mathrm{~N}$ 8.02. ${ }^{1} \mathrm{H}$ NMR $\left(25^{\circ} \mathrm{C}, \mathrm{CD}_{3} \mathrm{CN}\right.$, $400 \mathrm{MHz}): \delta(\mathrm{ppm})=8.67\left(\mathrm{~s}, 3 \mathrm{H}, \mathrm{H}_{\mathrm{A}}\right), 8.60\left(\mathrm{dd}, \mathrm{J}_{\mathrm{HH}}=1 \mathrm{~Hz}, 5 \mathrm{~Hz}, 3 \mathrm{H}, \mathrm{H}_{\mathrm{B}}\right)$ 8.02 (ddd, $\left.\mathrm{J}_{\mathrm{HH}}=1 \mathrm{~Hz}, 7 \mathrm{~Hz}, 3 \mathrm{H}, \mathrm{H}_{\mathrm{C}}\right), 7.61\left(\mathrm{~m}, 2 \mathrm{H}, \mathrm{H}_{\mathrm{D}}\right), 7.47(\mathrm{~m}, 6 \mathrm{H}$, $\left.\mathrm{H}_{\mathrm{E} / \mathrm{F} / \mathrm{G}}\right) .{ }^{19} \mathrm{~F}$ NMR $\left(25^{\circ} \mathrm{C}, \mathrm{CD}_{3} \mathrm{CN}, 376.5 \mathrm{MHz}\right): \delta(\mathrm{ppm})=-73.20\left(\mathrm{~d}, \mathrm{~J}_{\mathrm{FP}}=\right.$ $\left.707 \mathrm{~Hz}, \quad \mathrm{PF}_{6}\right)$. HRMS-ESI (m/z) calcd for $\mathrm{C}_{23} \mathrm{H}_{20} \mathrm{AgN}_{4}{ }^{120} \mathrm{Sn}_{1}$ ([Ag(1)(NCMe) $\left.]^{+}\right)$: 578.9761, found: 578.9764

Synthesis of $\left[\mathrm{CoCl}_{2}(\mathbf{1})(\mathrm{MeOH})\right]_{n}$; A Schlenk flask was charged with cobalt(II) chloride (18 mg, $0.14 \mathrm{mmol}$ ) in a nitrogen filled glove box. The solid was dissolved in methanol in air $(3 \mathrm{ml})$. To this, a solution of phenyltris(3-pyridyl)stannane (1) $(60 \mathrm{mg}, 0.14 \mathrm{mmol})$ in methanol $(3 \mathrm{ml})$ was added. The resulting pink solution was stirred at room temperature overnight. Slow evaporation of the solvent afforded a blue solid product. Recrystallisation by vapour diffusion from methanol/ether yielded $\left[\mathrm{CoCl}_{2}(\mathbf{1})(\mathrm{MeOH})\right]_{\mathrm{n}}$ as pink crystals (39 mg, $\left.0.066 \mathrm{mmol}, 47 \%\right)$. Characterisation of the product by NMR spectroscopy was impeded by its paramagnetism. Satisfactory elemental analysis could not be achieved due to partial loss of $\mathrm{MeOH}$ from the complex upon drying. The complex was only characterised by single-crystal $\mathrm{X}$-ray analysis.

Synthesis of $\left[\mathrm{CO}_{5}(\mathbf{1})_{6}\left(\mathrm{H}_{2} \mathrm{O}\right)_{6}(\mathrm{NCMe})_{6}\right]\left[\mathrm{BF}_{4}\right]_{10}$; A solution of phenyltris(3pyridyl)stannane (1) $(20 \mathrm{mg}, 0.047 \mathrm{mmol})$ in dichloromethane $(3 \mathrm{ml})$ was prepared in a narrow Schlenk flask. A solution of cobalt(II) tetrafluoroborate hexahydrate $(16 \mathrm{mg}, 0.047 \mathrm{mmol})$ in acetonitrile $(1 \mathrm{ml})$ was layered carefully on top of the solution of $\mathbf{1}$. The two layers were left to diffuse slowly at $-30{ }^{\circ} \mathrm{C}$, resulting in the growth of the product $\left[\mathrm{Co}_{5}(\mathbf{1})_{6}\left(\mathrm{H}_{2} \mathrm{O}\right)_{3}(\mathrm{NCMe})_{9}\right]\left[\mathrm{BF}_{4}\right]_{10}$ as pink needle-like crystals $(16.9 \mathrm{mg}$, $0.027 \mathrm{mmol}, 58 \%)$. Characterisation of the product by ${ }^{1} \mathrm{H}$ NMR spectroscopy was impeded by its paramagnetism. Satisfactory elemental analysis could not be achieved due to partial loss of coordinated solvent from the complex upon drying. ${ }^{11} \mathrm{~B} N M R\left(25^{\circ} \mathrm{C}, \mathrm{CD}_{3} \mathrm{CN}, 128.4 \mathrm{MHz}\right): \delta$ $(\mathrm{ppm})=32.86(\mathrm{~s}$, endo-BF 4$), 0.09\left(\mathrm{~s}\right.$, exo- $\left.\mathrm{BF}_{4}\right) \cdot{ }^{19} \mathrm{~F}$ NMR $\left(25^{\circ} \mathrm{C}, \mathrm{CD}_{3} \mathrm{CN}\right.$, $376.5 \mathrm{MHz}): \delta(\mathrm{ppm})=-112.75(\mathrm{~s}$, endo-BF 4$),-145.59\left(\mathrm{~s}\right.$, exo-$\left.-\mathrm{BF}_{4}\right)$

\section{Acknowledgements}

We thank the Leverhulme Trust (DSW, RGR, postdoctoral research grant for ALC), the Spanish MINECO-AEI and the EU (ESF) for a Ramon y Cajal contract (RG-R, RYC-2015-19035), the Spanish MCIU for funding (PGC2018-096880-A-I00, MCIU/AEI/FEDER, UE) and the Cambridge Trust (Vice Chancellor Scholarship for AJP). We also thank Diamond Light Source (UK, MT15768) for synchrotron X-ray data collection on $\left[\mathrm{CoCl}_{2}(\mathbf{1})(\mathrm{MeOH})\right]_{\mathrm{n}}$.

Keywords: tris(pyridyl) ligand • tin(IV) • supramolecular • coordination polymer $\bullet$ anion encapsulation

N. N. Adarsh, P. Dastidar, Chem. Soc. Rev. 2012, 41, 3039-3060.
R. Scopelliti, G. Bricogne, K. Severin, Chem. Sci. 2015, 6, 1004-1010.

[3] S. M. Jansze, G. Cecot, M. D. Wise, K. O. Zhurov, T. K. Ronson, A. M. Castilla, A. Finelli, P. Pattison, E. Solari, R. Scopelliti, et al., J. Am. Chem. Soc. 2016, 138, 2046-2054.

[4] Y.-J. Hou, K. Wu, Z.-W. Wei, K. Li, Y.-L. Lu, C.-Y. Zhu, J.-S. Wang, M. Pan, J.-J. Jiang, G.-Q. Li, et al., J. Am. Chem. Soc. 2018, 140, 18183-18191.

[5] R. Saha, D. Samanta, A. J. Bhattacharyya, P. S. Mukherjee, Chem. - A Eur. J. 2017, 23, 8980-8986.

[6] M. Hardy, N. Struch, F. Topić, G. Schnakenburg, K. Rissanen, A. Lützen, Inorg. Chem. 2018, 57, 3507-3515.

[7] Y. Uchida, K. Matsuoka, R. Kajita, Heteroat. Chem. 1997, 8, 439-449.

[8] J. Y. Ryu, E. H. Wi, M. Pait, S. Lee, P. J. Stang, J. Lee, Inorg. Chem. 2017, 56, 5471-5477.

[9] J. Y. Ryu, Y. J. Park, H.-R. Park, M. L. Saha, P. J. Stang, J. Lee, J. Am. Chem. Soc. 2015, 137, 13018-13023.

[10] S. Chen, K. Li, F. Zhao, L. Zhang, M. Pan, Y.-Z. Fan, J. Guo, J. Shi, C.-Y. Su, Nat. Commun. 2016, 7, 13169.

[11] J. Guo, Y.-W. Xu, K. Li, L.-M. Xiao, S. Chen, K. Wu, X.-D. Chen, Y.-Z. Fan, J.-M. Liu, C.-Y. Su, Angew. Chemie Int. Ed. 2017, 56, 3852-3856.

[12] R. García-Rodríguez, S. Hanf, A. D. Bond, D. S. Wright, Chem. Commun. 2017, 53, 1225-1228; b) A. GarciaRomero, A. J. Plajer, L. Alvarez-Miguel, A. D. Bond, D. S. Wright and R. Garcia-Rodriguez, Chem. -Eur. J., 2018, 24, 17019-17026.

[13] S. Hanf, R. García-Rodríguez, A. D. Bond, E. Hey-Hawkins, D. S. Wright, Dalt. Trans. 2015, 45, 276-283.

[14] A. J. Plajer, A. L. Colebatch, M. Enders, Á. García-Romero, A. D. Bond, R. García-Rodríguez, D. S. Wright, Dalt. Trans. 2018, 47, 7036-7043.

[15] M. A. Beswick, C. J. Belle, M. K. Davies, M. A. Halcrow, P. R. Raithby, A. Steiner, D. S. Wright, Chem. Commun. 1996 2619-2620.

[16] A. J. Plajer, A. L. Colebatch, F. J. Rizzuto, P. Pröhm, A. D. Bond, R. García-Rodríguez, D. S. Wright, Angew. Chemie Int. Ed. 2018, 57, 6648-6652.

[17] V. Bocokić, A. Kalkan, M. Lutz, A. L. Spek, D. T. Gryko, J. N. H. Reek, Nat. Commun. 2013, 4, 1-9.

[18] X. Wang, S. S. Nurttila, W. I. Dzik, R. Becker, J. Rodgers, J. N. H. Reek, Chem. - A Eur. J. 2017, 23, 14769-14777.

[19] M. S. Deshmukh, A. Yadav, R. Pant, R. Boomishankar, Inorg. Chem. 2015, 54, 1337-1345.

[20] M. S. Deshmukh, V. S. Mane, A. S. Kumbhar, R. Boomishankar, Inorg. Chem. 2017, 56, 13286-13292.

[21] A. M. Kluwer, I. Ahmad, J. N. H. Reek, Tetrahedron Lett. 2007, 48, 2999-3001.

[22] A. Krasovskiy, P. Knochel, Angew. Chemie - Int. Ed. 2004, 43, 3333-3336.

[23] M. Mantina, A. C. Chamberlin, R. Valero, C. J. Cramer, D. G. Truhlar, J. Phys. Chem. A 2009, 113, 5806-5812.

[24] J. K. Clegg, L. F. Lindoy, in Anion Coord. Chem. (Eds.: K. Bowman-James, A. Bianchi, E. García-España), 2011.

[25] R. Custelcean, Chem. Soc. Rev. 2010, 39, 3675-3685. 


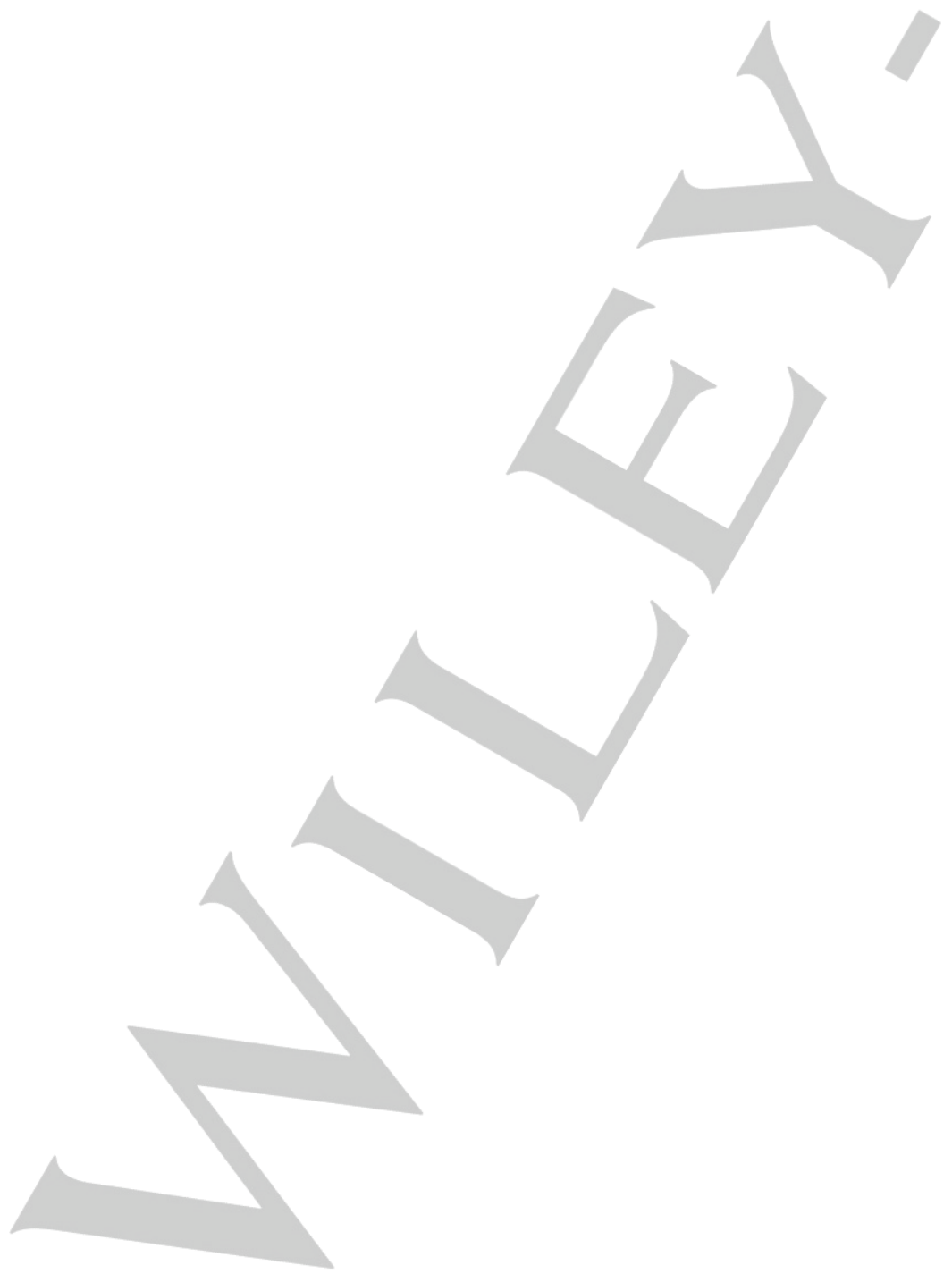




\section{Entry for the Table of Contents}

\section{FULL PAPER}

Simply Supra: the new, benchstable tris(3-pyridyl)stannane ligand $\mathrm{PhSn}(3-\mathrm{Py})_{3} \quad$ (3-Py = 3-pyridyl) provides simple access to a range of heterometallic $\mathrm{Sn}(\mathrm{IV}) /$ transition metal complexes. Discrete molecular arrangements involving anion encapsulation are observed in the presence of weakly coordinating anions, while coordination polymers are formed where coordinating anions are involved.
E. S. Yang, A. J. Plajer, Á. GarcíaRomero, A. D. Bond, T. K. Ronson, C. M. Álvarez, R. García-

Rodríguez, * A. L. Colebatch* and D. S. Wright ${ }^{\star}$

Page No. - Page No.

A tris(3-pyridyl)stannane as a new building block for heterobimetallic coordination polymers and supramolecular cages 